\title{
Intertemporal Model of Co-Existence of Two Rival Species: A Case of Vampires and Humans Co-Habitation
}

\author{
Wadim Strielkowski ${ }^{1}$, Evgeny Lisin ${ }^{2}$, Emily Welkins ${ }^{3}$ \\ ${ }^{1}$ Institute of Economic Studies, Faculty of Social Sciences, Charles University in Prague, Prague, Czech Republic \\ ${ }^{2}$ Moscow Power Engineering Institute (Technical University), Moscow, Russia \\ ${ }^{3}$ University of Strasbourg, Strasbourg, France \\ Email: strielkowski@fsv.cuni.cz, lisinym@mpei.ru, emily.welkins@gmail.com
}

Received October 9, 2012; revised November 11, 2012; accepted November 20, 2012

\begin{abstract}
This article presents a serious analysis of a ridiculous subject. It provides a new approach to modeling intertemporal interactions between vampires and humans based popular fiction literature, comic books, films and TV series. It is mainly concerned with the following question: would peaceful co-existence of humans and vampires be possible from a scientific point of view? And if so, why do not humans encounter vampires more often. Mathematical modeling enables us to conclude that several popular culture sources outline the models describing plausible and peaceful vampire and human co-existence.
\end{abstract}

Keywords: Supernatural Economics; Mathematical Modeling; Popular Culture; Predator-Prey System; Vampires

\section{Introduction}

Vampires as well as the economic significance of vampirism and optimal bloodsucking strategies (e.g. preventing the depletion of renewable human resources) made their way into the mainstream research literature becoming an inspiration for several academic papers (e.g. [1-4]).

The description of vampires, the man's natural predators, can be found in legends and folklore. The word "vampire" itself is considered to originate in Hungarian language where it is spelled as "vampir". The first myths and legends about vampires probably existed at the dawn of human history. In the 19th century, ancient Mesopotamian texts dating back to 4000 B.C. were translated into English revealing some mentioning of "seven spirits" that are very much like the description of vampires as we think of them today [5].

The fact that vampires constituted a threat to humans throughout the history of mankind (whether this threat was real or imaginary) can be shown on the examples of recent archaeological findings at ancient burial sites where some human remains showed signs of being staked, strapped or gagged with a stone, a typical way to slay the vampire according to the superstitious beliefs.

The vampire metaphor in economics can be found in the works of Karl Marx and his followers. For instance,
Carver [6] noted that Marx used the vampire metaphor at least three times in "Capital". For example, in one of the cases Marx describes British industry as "vampire-like" which "could but live by sucking blood, and children's blood too" [7].

Marx's colleague and long-time sponsor Frederick Engels also used the vampire metaphor in his writing. In one of his works entitled "The Condition of the Working Class in England", Engels identified and blamed the "vampire property-holding class" as the source of all social troubles [8].

Marx described vampires' habits, their greediness and their lounging for blood with such vividness that it often crossed the boundaries of the mere metaphor. Although many researchers perceive Marx's vampires as a metaphoric abstract of bourgeois bloodsuckers feeding on working people (see $[9,10])$ Marx's knowledge of vampires was very detailed. Frayling [11] states that in one particular case, when describing Wallachian peasants performing forced labour for their boyars, Marx refered to one specific "boyar" who was "drunk with victory" and who might had been no one but Wallachian prince Vlad (called "The Impaler")—or well-known Count Dracula from the eponymous book. This is very peculiar because Bram Stoker's "Dracula", did not see the light of the day until 1897, some 14 years after Marx's death.

This brings us to the point of posing a question: would 
it be possible for vampires to peacefully co-exist with humans? Starting from Bram Stoker's "Dracula", the theme of vampirism has been widely exploited by many authors: Stephen King, Anne Rice, Stephenie Meyer, Elizabeth Kostova or Charlaine Harris, just to name a few. In addition to that, vampires often appear in comic books and films and TV series based on these books (e.g. "Buffy the Vampire Slayer"). We reviewed some of the popular literature sources, comic books, and films on vampires and identified four types of scenarios describeing vampire-human interactions. These scenarios were used to draw models of vampire-human confrontation using the predator-prey model specified above.

\section{The Stoker Model}

Bram Stoker's "Dracula" describe interactions between vampires and humans in the following way: a vampire selects a human victim and gets into its proximity (it typically happens after dark and the vampire needs the victim to invite her/him in). Often the vampire does not require permission to enter the victim's premises and attacks the sleeping victim $[12,13]$. The vampire bites the victim and drinks the victim's blood, then returns to feed for 4 - 5 consecutive days, whereupon the victim dies, is buried and rises to become another vampire (unless a wooden stake is put through its heart). Vampires usually need to feed every day, so more and more human beings are constantly turned into vampires [14].

Assume the events described in "Dracula" were real. How would things evolve given the Stoker model dynamics described in both sources? Let us take 1897 as the starting point (i.e. the year Stoker's novel was first published). In 1897, the world population was about 1650 million people [15].

The initial conditions of the Stoker model are the following: 1 vampire, 1650 million people, there are no organized groups of vampire slayers. The date we choose for the first vampire has little bearing on our argument and therefore can be set arbitrarily. The model can be presented in a form of a diagram (Diagram 1).

Where $\mathrm{H}$ denotes humans and $\mathrm{V}$ denotes vampires, $\mathrm{HO}$ is the initial state of human population, $\mathrm{v} 0$ is the initial state of vampire population and the aHV describes an interaction between a human and a vampire (with a as the

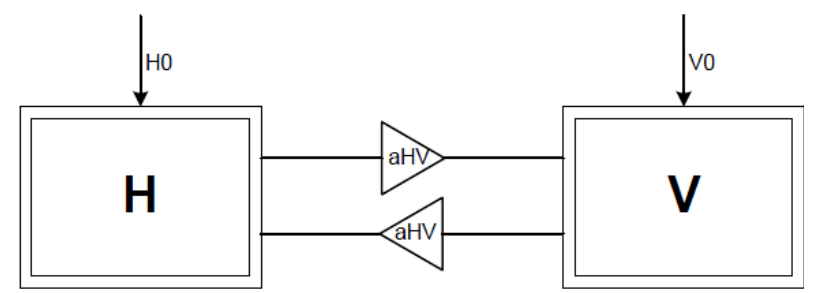

Diagram 1. The stoker model. coefficient of a lethal outcome for vampire-human interaction for humans).

Let us calibrate the parameters of this specific (vampiric) case of predator-prey model. The calculation period is set at 1 year with a step of 5 days $(t=0 \cdots 73)$. The coefficient of human population growth $k$ for the given period is very small and can be neglected, therefore $k=0$. The coefficient of lethal outcome for humans interacting with vampires can be calculated according to the scenario presented in the Stoker-King mode $y_{0}(t)=$ $y_{0} q^{t}$, where $y_{0}=1, q=2$. The probability of a human being turned into a vampire is very high, thence $b=1$. Jonathan Harker and Abraham van Helsing could not be, by all means, considered efficient vampire slayers, therefore we can put $c=0$.

The resulting model can be presented in a form of the following Cauchy problem:

$$
\left\{\begin{array}{l}
\frac{\mathrm{d} x}{\mathrm{~d} t}=-a x y \\
\frac{\mathrm{d} y}{\mathrm{~d} t}=a x y \\
x(0)=1.65 \times 10^{9} \\
y(0)=1
\end{array}\right.
$$

Due to the fact that the total sum of humans and vampires does not change in time (human population does not grow and humans gradually become vampires), the predator-prey model is diminished to a simple problem of an epidemic outbreak [16].

It can be assumed that for any moment $t$ there holds an equality $x(t)+y(t)=x_{0}+y_{0}$, where $x_{0}=1.65 \times 10^{9}$. The system of differential equations can be presented in a form of a single differential equation:

$$
\frac{\mathrm{d} y}{\mathrm{~d} t}=a x(t) y(t)=a y(t)\left[y_{0}+x_{0}-y(t)\right],
$$

with the initial condition $y(0)=y_{0}=1$.

This equation belongs to the class of logistic equations (e.g. the Verhulst equation that describes the growth of population). Solving the Cauchy problem for this equation yields:

$$
\begin{aligned}
& \frac{\mathrm{d} y}{y\left[x_{0}+y_{0}-y\right]}=a \mathrm{~d} t \\
& \Rightarrow \frac{\mathrm{d} y}{y}+\frac{\mathrm{d} y}{y_{0}+x_{0}-y}=\left(y_{0}+x_{0}\right) a \mathrm{~d} t \\
& \Rightarrow \ln (y)-\ln \left(y_{0}+x_{0}-y\right) \\
& \quad=\ln y_{0}-\ln \left(y_{0}+x_{0}-y_{0}\right)+a\left(y_{0}+x_{0}\right)\left(t-t_{0}\right) \\
& \Rightarrow \ln \left[\frac{y}{y_{0}+x_{0}-y}\right]=\ln \left[\frac{y_{0}}{x_{0}}\right]+a\left(y_{0}+x_{0}\right)\left(t-t_{0}\right) \\
& \Rightarrow \frac{y}{y_{0}+x_{0}-y}=\frac{y_{0}}{x_{0}} \mathrm{e}^{a\left(y_{0}+x_{0}\right)\left(t-t_{0}\right)}
\end{aligned}
$$


By solving the problem above we get the following equation:

$$
y(t)=\frac{\left(x_{0}+y_{0}\right) y_{0}}{y_{0}+x_{0} \mathrm{e}^{-\alpha\left(y_{0}+x_{0}\right)\left(t-t_{0}\right)}} t \geq 0
$$

The solution clearly shows that with passing time the number of vampires grows and very soon there are no humans left: $\lim _{t \rightarrow \infty} y(t)=x_{0}+y_{0}$.

The solution to this problem is presented below (Figure 1). It is clearly visible that the human population is drastically reduced by $80 \%$ by the 165 th day from the moment when the first vampire arrives. This means that the human population reaches its critical value and practically becomes extinct (following the definitions of "Critically Endangered species" by the International Union for Conservation of Nature) [17]. At that precise moment, the world will be inhabited by 1384 million vampires and 266 million people.

In order to determine the moment of time when the speed of vampire population's growth reaches its maximal values, we need to consider the following magnitude: $\mathrm{d}^{2} y / \mathrm{d} t^{2}$ :

$$
\begin{aligned}
& \frac{\frac{\mathrm{d}^{2} y}{\mathrm{~d} t^{2}}}{\left[y_{0}+x_{0} \mathrm{e}^{-a\left(y_{0}+x_{0}\right)\left(t-t_{0}\right)}\right]^{3}}
\end{aligned}
$$

The maximal growth of the number of vampires (infected humans) will be observed in a moment of time $t_{\text {max }}$ :

$$
t_{\text {max }}=\frac{\ln \left(x_{0} / y_{0}\right)}{a\left(y_{0}+x_{0}\right)}+t_{0},
$$

where $t_{\max }=153$ is the day (153rd day) when the number of vampires is the highest, $x\left(t_{\max }\right)=825$ million is the number of vampires in a moment of time $t_{\max }$, $x^{\prime}\left(t_{\max }\right)=268$ million is the number of newly turned vampires in day $t_{\max }$.

Therefore, the Stoker model describes the "explosive"

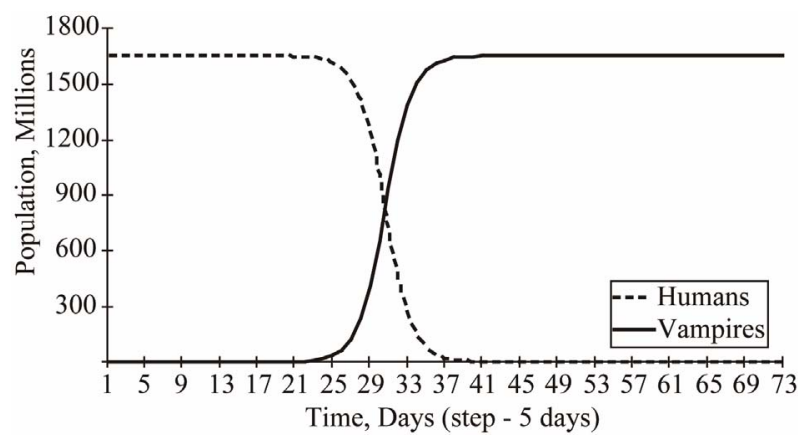

Figure 1. The change in the numbers of humans and vampires in time ( 1 step = 5 days) in the Stoker-King model. growth of vampire population. Within the two months of Dracula's arrival to England, there would have been 4 thousand vampires in operation. The model analyzed in this scenario is very similar to an epidemic outbreak caused by a deadly virus (e.g. Ebola or SARS). According to the Stoker model, vampires need just half a year to take up man's place in nature. Therefore, under this scenario the co-existence of humans and vampires seems highly unrealistic.

\section{The Harris-Meyer-Kostova Model}

Stephenie Meyer's “Twilight series”, Charlaine Harris's "Sookie Stockhouse (Southern Vampire) series", "True Blood" (TV series) and Elizabeth Kostova's "The Historian" show the world where vampires peacefully co-exist with humans.

In Stephenie Meyer's “Twilight series” vampires can tolerate the sunlight, interact with humans (even fall in love with them) and drink animals' blood to survive [18]. In "True Blood" TV series, however, a world is shown where vampires and humans live side-by-side and are aware of each other. Vampires can buy synthetic blood of different blood types [19] that is sold in bottles and can be bought in every grocery store, bar or gas station. Humans also find use of vampires "essence-vampires" blood (called "V") is a powerful hallucinogenic drug that is sought by humans and traded on the black market (sometimes humans capture vampires with the help of silver chains or harnesses and then drain their blood). There is a possibility to turn a human being into a vampire, but it takes time and effort (as described in the Rice model). In Elizabeth Kostova's novel "The Historian", vampires are rare although real and do not reveal themselves to humans too often (except for the librarians whom for whom they seem to have a strange passion) [20].

Assume that at the time of the events described in the first book of the "Sookie Stackhouse Series", "Dead Until Dark” (2001), the world's vampire hypothetical population was around five million (the population of the state of Louisiana in 2001 we arbitrarily use in our model) [21]. The initial conditions of the Harris-Meyer-Kostova model are the following: five million vampires, 6159 million people, there are organized groups of vampire "drainers". The model can be presented in a form of a diagram (Diagram 2).

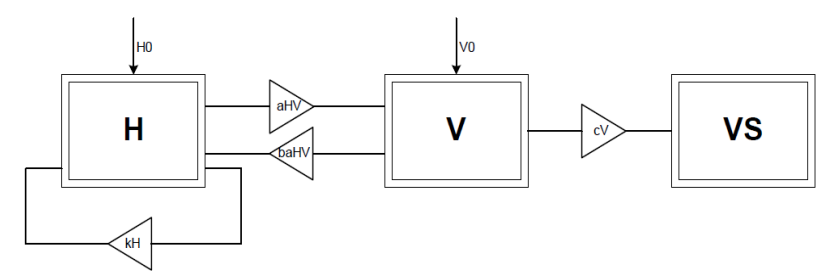

Diagram 2. The Harris-Meyer-Kostova model. 
where $\mathrm{H}$ denotes humans, $\mathrm{V}$ denotes vampires and VS denotes vampire slayers. $\mathrm{H} 0$ is the initial state of human population, $\mathrm{kH}$ denotes the exponential growth of human population, v0 is the initial state of vampire population, $\mathrm{aHV}$ and baHV both describe interactions between a human and a vampire (with a as the coefficient of a lethal outcome for vampire-human interaction for humans and $\mathrm{b}$ as the coefficient describing the rate with which humans are turned into vampires) and $\mathrm{cV}$ denotes the death rate for vampires.

Let us calibrate the parameters of this specific case of predator-prey model. The calculation period is set at 100 years with a step of 1 year $(t=2001 \cdots 2101)$. The coefficient of human population growth is calculated as

$k=\frac{\ln \left(x_{1} / x_{0}\right)}{t_{1}-t_{0}}$ where $x_{1}=7000$ million people at a moment of time $t_{1}=2012, x_{0}=6150$ million of people at time $t_{0}=2001$. Humans almost always come out alive from their encounters with vampires, hence the coefficient of lethal outcome $a$ will be low and is denoted by $0.01 \cdot a$. The probability of a human being turned into a vampire is similar to the on in the Rice model and equals to $b=0.1$. There are numerous groups of vampire "drainers" (although the number of drained vampires is relatively low and would not lead to their total extincttion), therefore we can put $c>0$ ( $c$ is calculated similarly to the coefficient $k$ ). The resulting model is presented in the initial set-up of predator-prey framework:

$$
\left\{\begin{array}{l}
\frac{\mathrm{d} x}{\mathrm{~d} t}=x(k-a y) \\
\frac{\mathrm{d} y}{\mathrm{~d} t}=y(b a x-c) \\
x(0)=6150 \times 10^{6} \\
y(0)=5 \times 10^{6}
\end{array}\right.
$$

The model allows for a stationary solution: there are system parameters $\left(x_{s}, y_{s}\right)$ that would stabilize the populations of humans and vampires in time. In order to find the stabilized populations of both spices, $x_{s}$ and $y_{s}$, an equality described in (10) might be employed: $\left(x_{s}, y_{s}\right)=$ $(77,048)$ million individuals.

This stationary solution for 2001 cannot be found with the chosen population growth coefficient $k$ and can be reached applying some conditions only after 2012. The deviations in the number of people and vampires from the stationary state at the initial period of time are quite small which points at the fact that the system might be stable and auto-cyclical. This is proved by the further calculations (Figures 2 and $\mathbf{3}$ ).

It is apparent from both charts above that the human population will be growing until 2046 when it reaches its peak of 9.6 billion people, whereupon it will be declining

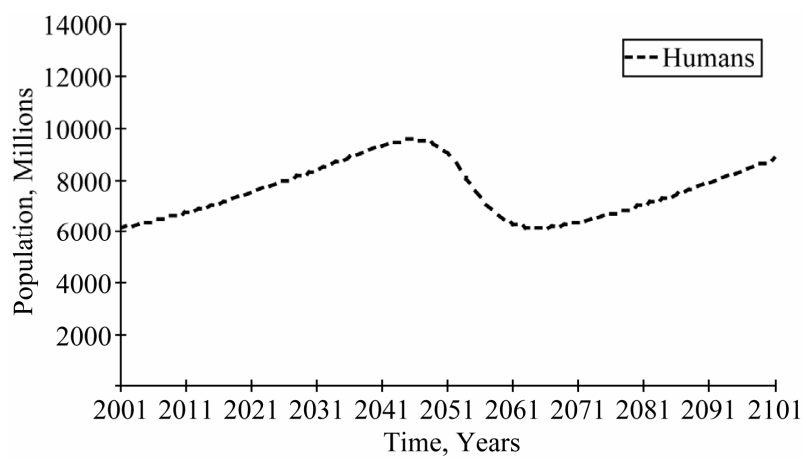

Figure 2. The change in the number of humans in the Harris-Meyer-Kostova model (cyclical nature).

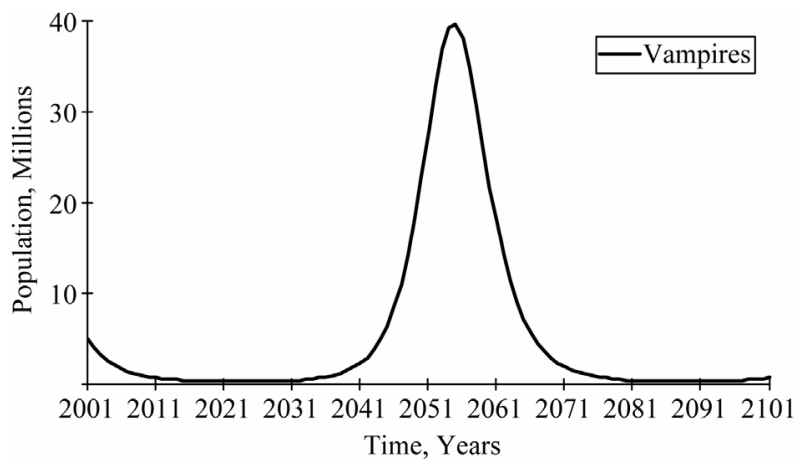

Figure 3. The change in the number of vampires in the Harris-Meyer-Kostova model (cyclical nature).

until 2065 until it reaches its bottom at 6.12 billion people. This process will repeat itself continuously ${ }^{1}$. The vampire population will be declining until 2023 when it reaches its minimum of 289 thousand vampires, whereupon it will be growing until 2055 until it reaches its peak at 397 million vampires. This process will repeat itself continuously.

In might be shown that under certain conditions, the Harris-Meyer-Kostova model seems plausible and allows for the existence of vampires in our world. Peaceful co-existence of two spices is a reality. However, this symbiosis is very fragile and whenever the growth rate of human population slows down, the blood thirst of vampires accelerates, or vampire drainers become too greedy, the whole system shutters with just one population remaining.

\section{The Whedon Model}

So, if the peaceful co-existence of humans and vampires is possible, why are not vampires living amongst us, either as the bourgeoisie class, as described in the works of Marx, or hidden, as shown in the recent Hollywood blockbuster by Timur Bekmambetov?

\footnotetext{
${ }^{1}$ According to the UN Population prognoses, the population of Earth will reach 9.1 billion people by 2050 .
} 
The answer might lie in the existence of effective vampire slayers. Vampires are similar to an infectious disease and should be eliminated quickly and without mercy in order not to cause the world pandemic as shown in the recent work of Strielkowski, Lisin and Welkins [22].

The creator of "Buffy the Vampire Slayer" (TV series), Joss Whedon, presents the most simplistic, yet the most dreadful "doomsday" scenario of vampire-human interaction (similar to Zombie infection outbreak shown in cult-status fiction movies, such as "28 days later" or "Resident Evil"). The vampire bites its victim who (in a very short period of time) rises as another undead vampire and, in turn, bites another human victim, and so on. Luckily enough for humans, the world is populated by an unknown (but considerably large) number of vampire slayers (with a girl named Buffy Summers being their most remarkable representative) [23]. Killing a vampire according to the Whedon model is relatively easy: using a wooden stake, a crucifix or a variety of other methods is efficient.

The Whedon model is a modified version of the Harris-Meyer-Kostova model. In addition to the original model, it uses the higher coefficient of vampire-slaying effectiveness, $c$. The model reveals how unstable the equilibrium reached in Meyer-Harris-Kostova model might be.

The initial conditions of the Whedon model are the following: five million vampires, 6159 million people, there are organized groups of zealot vampire slayers (who kill vampires not just for profit but in an altruistic attempt to save mankind). The model can be presented in a form of a diagram (Diagram 3), where $\mathrm{H}$ denotes humans, $\mathrm{V}$ denotes vampires and VS denotes vampire slayers. H0 is the initial state of human population, $\mathrm{kH}$ denotes the exponential growth of human population, $\mathrm{v} 0$ is the initial state of vampire population, aHV and baHV both describe interactions between a human and a vampire (with a as the coefficient of a lethal outcome for vampire-human interaction for humans (which is higher this time) and $b$ as the coefficient describing the rate with which humans are turned into vampires) and $\mathrm{cV}$ denotes the death rate for vampires (with a much more higher c).

Let us calibrate the parameters of the model. The calculation period is set at 10 years with a step of 1 year $(t=$ 2001 ‥ 2101). The coefficient of human population's

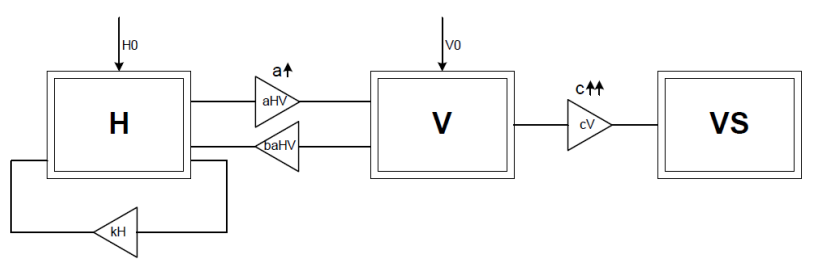

Diagram 3. The Whedon model. growth is calculated as $k=\frac{\ln \left(x_{1} / x_{0}\right)}{t_{1}-t_{0}}$ where $x_{1}=7000$ million of people at a moment of time $t_{1}=2012, x_{0}=$ 6150 million of people at time $t_{0}=2001$. Humans are almost always turned into new vampires, therefore the coefficient of lethal outcome is high and it is denoted by $a$. The probability of a human turned into a vampire is $b$ $=0.1$. There are numerous groups of vampire slayers, therefore we put $10 \cdot \mathrm{c}$. The resulting model is presented on Figures 4 and 5.

Although the model described in (5) allows for the stationary solution, the initial conditions of the problem lead to the disbalance in the system. The Whedon model is too unstable to be realistic. Vampires and humans cannot co-exist for a long period of time because human vampire slayers exterminate all vampires entirely. The human population recovers from the damage caused to it by vampires and continues to grow steadily.

Even though the Whedon model's structure theoreticcally allows for co-existence of humans and vampires, the laborious vampire slayers contribute to putting the system out of balance by killing all vampires. This outcome is predetermined by the initial parameters of the Whedon model (vampires constantly need to feed, cannot effectively control their blood thirst and attack humans

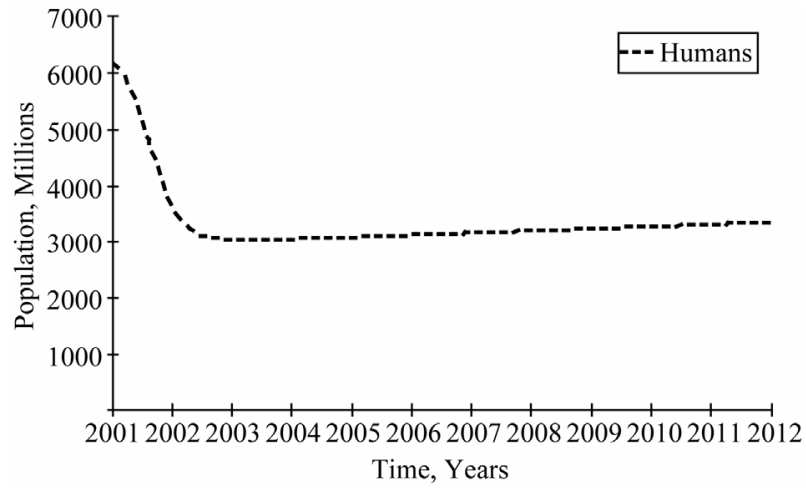

Figure 4. Changes in human population in the Whedon model (disbalance, human population recovers).

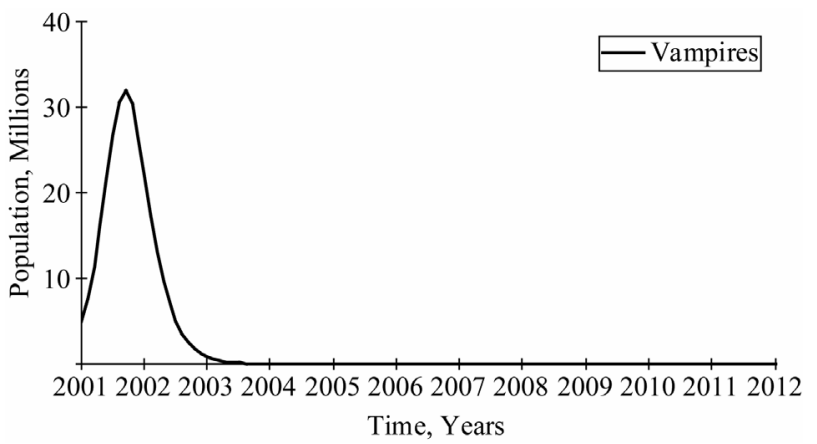

Figure 5. Changes in vampire population in the Whedon model (disbalance, vampires are exterminated). 
whenever possible).

A very important feature of the Whedon model is for the vampire slayers to exterminate all vampires before they do an irreversible damage to the human population and it will fail to return to its initial state and continue to grow steadily and peacefully.

\section{Conclusions}

In this article we presented models of intertemporal interactions between vampires and humans to analyze the possibility of co-existence for human and vampire populations in three different scenarios described by the conditions narrated in popular literature and films. It appears that although vampire-human interactions would in most cases lead to great imbalances, there are several cases that might actually convey plausible models of co-existence between humans and vampires.

Overall, although mathematical principles enabled us to doubt the realism of many human and vampire encounters described in the economic literature, several sources provide what might be an acceptable description of the situation in which vampires and humans co-exist in a world that is very similar to the one we live in. This makes us to believe that the vampire metaphor frequently used in by some economists, might actually have some grounds in real life and is not just a product of superstitious beliefs.

\section{REFERENCES}

[1] C. J. Efthimiou and S. Gandhi, "Cinema Fiction vs Physics Reality: Ghosts, Vampires and Zombies,” Sceptical Inquirer, Vol. 31. No. 4, 2007, p. 27.

[2] R. F. Hartl and A. Mehlmann, "The Transylvanian Problem of Renewable Resources," Revue Francaise d'Automatique, Informatique et de Recherche Operationelle, Vol. 16, No. 4, 1982, pp. 379-390.

[3] R. F. Hartl and A. Mehlmann, "Convex-Concave Utility Function: Optimal Blood Consumption for Vampires," Applied Mathematical Modelling, Vol. 7, No. 2, 1983, pp. 83-88. doi:10. 1016/0307-904X(83)90117-8

[4] R. F. Hartl, A. Mehlmann and A. Novak, "Cycles of Fear: Periodic Bloodsucking Rates for Vampires,” Journal of Optimization Theory and Application, Vol. 75, No. 3 1992, pp. 559-568. doi:10. 1007\%2FBF00940492

[5] R. C. Thompson, "The Devils and Evil Spirits of Babylonia”, 1st Edition, Vol. 2, Luzac, London, 1904.

[6] T. Carver, “The Postmodern Marx," 1st Edition, Man- chester University Press, Manchester, 1998.

[7] K. Marx, "Das Kapital, Kritik der Politischen Ökonomie (Capital: Critique of Political Economy),” Verlag Von Otto Meisner, Hamburg, 1867.

[8] F. Engels, "The Condition of the Working Class in England in 1844,” Otto Wigand, Leipzig, 1845.

[9] J. Derrida, "Specters of Marx: The State of the Debt, the Work of Mourning, and the New International," Routledge, Abingdon, 1994.

[10] M. Neocleous, "The Political Economy of the Dead: Marx's Vampires," History of Political Thought, Vol. XXIV, No. 4. 2003, pp. 668-684.

[11] C. Frayling, "Vampyres: Lord Byron to Count Dracula," 1st Edition, Faber \& Faber, London, 1992.

[12] B. Stoker, "Dracula," 1st Edition, Archibald Constable and Company, London, 1897.

[13] R. T. McNally and R. Florescu, "In Search of Dracula," Houghton Mifflin Company, New York, 1994.

[14] S. King, “'Salem’s Lot,” Doubleday \& Company, New York, 1975.

[15] United Nations: Department of Economic and Social Affairs, Population Division, "The World at Six Billion," United Nations, New York, 1999.

http://www.un.org/esa/population/publications/sixbillion/ sixbillion.htm

[16] P. Munz, I. Hudea, J. Imad and R. J. Smith, "When Zombies Attack!: Mathematical Modelling of an Outbreak of Zombie Infection,” In: J. M. Tchuenche and C. Chiyaka, Eds., Infectious Disease Modelling Research Progress, Ottawa University Press, Ottawa, 1999, pp. 133-150.

[17] IUCN, "Red List of Threatened Species," The World Conservation Union, IUCN Gland, Switzerland and Cambridge, 2012. http://www. iucnredlist. org

[18] S. Meyer, “Twilight Saga,” 1st Edition, Little Brown, New York, 2008.

[19] C. Harris, “The Sookie Stackhouse Chronicles,” Reprint Edition, Ace Trade, Berkeley, 2010.

[20] E. Kostova, “The Historian,” 1st Edition, Little Brown, New York, 2005.

[21] A. Maddison, "The World Economy: Historical Statistics,” OECD Development Centre, Paris, 2004.

[22] W. Strielkowski, E. Lisin and E. Welkins, "Dynamics of Growth in Human Population: The Effect of Infectious Diseases,” Social and Natural Sciences Journal, Vol. 5, 2012.

http://general.journals.cz/documents/Vol5/strielkowski.pd $\mathrm{f}$

[23] J. Whedon, "Buffy the Vampire Slayer (TV series),” Mutant Enemy Production, 1997. 